\title{
Exposure of harbour seals Phoca vitulina to Brucella in declining populations across Scotland
}

\author{
Joanna L. Kershaw ${ }^{1, *}$, Emma J. Stubberfield ${ }^{2}$, Geoffrey Foster ${ }^{3}$, Andrew Brownlow ${ }^{3}$, \\ Ailsa J. Hall ${ }^{1}$, Lorraine L. Perrett ${ }^{2}$ \\ ${ }^{1}$ Sea Mammal Research Unit, Scottish Oceans Institute, University of St Andrews, St Andrews, Fife, KY16 8LB, UK \\ ${ }^{2}$ Dept. of Bacteriology, Animal and Plant Health Agency (APHA), New Haw, Addlestone, Surrey, KT15 3NB, UK \\ ${ }^{3}$ Scottish Marine Animals Strandings Scheme, SAC Consulting Veterinary Services, Inverness, IV2 4JZ, UK
}

\begin{abstract}
Since 2000 there has been a major decline in the abundance of Scottish harbour seals Phoca vitulina. The causes of the decline remain uncertain. The aim of this study was to establish the extent to which the seals in the regions of greatest decline have been exposed to Brucella, a bacterial pathogen that causes reproductive failure in terrestrial mammalian hosts. Tissues from dead seals collected between 1992 and 2013 were cultured for Brucella $(\mathrm{n}=150)$. Serum samples collected from live capture-released seals $(\mathrm{n}=343)$ between 1997 and 2012 were tested for Brucella antibodies using the Rose Bengal plate agglutination test (RBT) and a competitive enzyme-linked immunosorbent assay (cELISA). In total, $16 \%$ of seals cultured had Brucella isolated from one or more tissues, but there were no pathological signs of infection. The cELISA results were more sensitive than the RBT results, showing that overall $25.4 \%$ of seals were seropositive, with the highest seroprevalence in juveniles. As there was no evidence of either a higher seroprevalence or higher circulating antibody levels in seropositive animals in the areas with the greatest declines, it was concluded that Brucella infection is likely not a major contributing factor to recent declines. However, the consistently high proportion of seals exposed to Brucella indicates possible endemicity in these populations, likely due to $B$. pinnipedialis, which has demonstrated a preference for pinniped hosts. Importantly, given the close proximity between seals, humans and livestock in many areas, there is the potential for cross-species infections.
\end{abstract}

KEY WORDS: Pinnipeds · Brucella $\cdot$ Disease $\cdot$ Cultures $\cdot$ Seroprevalence $\cdot$ Antibodies $\cdot$ ELISA Rose Bengal plate agglutination test

\section{INTRODUCTION}

Aerial surveys have been carried out by the Sea Mammal Research Unit, to monitor harbour seal Phoca vitulina populations around Scotland since 1985, and declines in a number of these populations have been seen since 2000 (Lonergan et al. 2007). Major declines of $68 \%$ in Orkney, $50 \%$ in Shetland, and $90 \%$ in the Firth of Tay have been documented in particular (SCOS 2012). However, the pattern of the declines is not universal, as some areas remain more stable while the populations in other areas con-

${ }^{*}$ Corresponding author: jk49@st-andrews.ac.uk tinue to decrease in size. The population in the Eden and Firth of Tay Special Area of Conservation, for example, has experienced the most dramatic and sustained declines of over $90 \%$ in the last $15 \mathrm{yr}$, with a most recent estimate of just 29 individuals left in 2014 (Hanson et al. 2017).

Many potential causes of the decline have been suggested, but the contributing factors remain uncertain. Some of these include predation by killer whales (Bolt et al. 2009), competition for food with other marine top predators (SCOS 2012), exposure to biotoxins from harmful algal blooms (Hall \& Frame 
2010), deliberate shooting (Thompson et al. 2007), accidental mortalities as a result of interactions with shipping vessels (Thompson et al. 2010) and predation by grey seals Halichoerus grypus (Brownlow et al. 2016). A further potential contributing factor to these declines is infectious disease, but there has been a lack of reports of sick animals by the Scottish Marine Animals Strandings Scheme (SMASS) or the Scottish Society for the Prevention of Cruelty to Animals (SSPCA). This suggests that if infectious disease was present in these populations, and was contributing to the observed declines, it could either be affecting the reproductive success of the animals, or causing them to die very quickly once infected, or both. A particular infectious agent of interest in this respect is Brucella as it is known to cause reproductive failure in other mammalian hosts. The aim of this study was to establish the extent to which harbour seals in Scotland have been exposed to Brucella over time, both before and during the observed population declines, and whether this could be a potential contributing factor to the major declines in some areas.

Members of the genus Brucella are Gram-negative, rod-shaped bacteria that cause chronic disease most commonly associated with abortions and infertility in domestic livestock (Seleem et al. 2010). Since the first reports of Brucella in a marine mammal in 1994 (Ross et al. 1994), infections have been recognised in a range of pinniped and cetacean species worldwide (Thakur et al. 2012). Strains isolated from marine mammals have been shown to be phenotypically and genetically distinct from those isolated from terrestrial mammals, and 2 species have been described that have pinnipeds and cetaceans as their preferred hosts: $B$. pinnipedialis and B. ceti, respectively (Foster et al. 2007). B. ceti infections in cetaceans have been associated with various pathologies which include abortions and neonatal mortality (Miller et al. 1999), epididymitis in males (Dagleish et al. 2008), meningoencephalitis (González et al. 2002, Jauniaux et al. 2010, Alba et al. 2013, Garofolo et al. 2014), abscesses (Foster et al. 1996, Foster et al. 2002), endocarditis (González-Barrientos et al. 2010), mastitis, pneumonia, peritonitis, osteomyelitis and spinal discospondylitis (Foster et al. 2002). In contrast, pathology associated with $B$. pinnipedialis in seals is lacking despite several reports of its isolation (Foster et al. 2002, Tryland et al. 2005, Nymo et al. 2011, Siebert et al. 2017).With respect to harbour seals specifically, Brucella has previously been isolated from wild animals (Ross et al. 1994, Garner et al. 1997, Foster et al. 2002, Prenger-Berninghoff et al. 2008), and in several areas they have also been found to be seropositive (Ross et al. 1996, Maratea et al. 2003, Gaydos et al. 2005, Hueffer et al. 2013). However, the extent to which harbour seals in Scotland, or the United Kingdom in general, have been exposed to this pathogen since the onset of the declines is unknown. Here, tissue samples from dead harbour seals collected by the SMASS over 20 yr were cultured to test for Brucella isolates. In addition, harbour seal serum samples from live capture-release studies by the Sea Mammal Research Unit over a $14 \mathrm{yr}$ period were tested for Brucella antibodies. Tempo-spatial patterns in seroprevelance were examined in order to investigate the potential role of Brucella as a contributing factor to the Scottish harbour seal declines.

\section{MATERIALS AND METHODS}

\section{Brucella cultures}

Tissue samples from 150 dead harbour seals from across Scotland which had received post mortem examination were collected by the SMASS between 1992 and 2013 as part of systematic surveillance studies. Microbiological culture was performed, including specific methods for Brucella isolation. The selected tissues varied between animals but typically included lung, liver, kidney, spleen and small intestine, but also brain, pancreas, reproductive tissue, various lymph nodes and any abscesses apparent at post mortem. These were collected from approximately equal numbers of males $(\mathrm{n}=61)$, females ( $\mathrm{n}=$ 41 ) and unsexed animals ( $n=48)$. The majority of cases were adult animals although some juveniles were also sampled. Tissues were processed using a standardised method (Foster et al. 2002) and cultured on Columbia sheep blood agar (CSBA; Oxoid) and Farrell's medium incubated at $37^{\circ} \mathrm{C}$ in air with $5 \%$ added $\mathrm{CO}_{2}$. Isolates with colonial appearance typical of Brucella on either medium were identified as Brucella using phenotypic tests as previously described (Foster et al. 2002). A multi-locus variable number of tandem repeats analysis (MLVA-16) was used to confirm species designation (Maquart et al. 2009).

\section{Serum sampling procedure}

Blood samples were collected from 343 live-captured harbour seal adults, juveniles $(<50 \mathrm{~kg}$ and/or $120 \mathrm{~cm}$ ) and suckling pups from multiple haul out sites around 5 areas of Scotland: the South East (the 
Eden Estuary, the Firth of Tay and the Firth of Forth), the North East (the Moray Firth, Dornoch Firth, Loch Fleet and the Pentland Firth), the North West (the Isle of Skye, Loch Shieldaig, and the Loch Nan Uamh Islands), the South West (the Sound of Jura and south east Islay), and Orkney (Fig. 1). Samples were collected between 1997 and 2012 at varying times of the year. Due to the opportunistic nature of the analysis of stored samples, sample sizes varied regionally, across years and between age classes, although the male to female ratio was approximately equal with 182 males and 160 females (Table 1). The seals were captured in nets on haul outs or in the water, and were sedated with Zoletil 100 (Virbac) at a dose rate of $0.5 \mathrm{ml}$ per $100 \mathrm{~kg}$ body weight intravenously. Blood samples were taken from the extradural vein immediately after the immobilisation of the animal. The whole blood samples were spun, sera was collected, and aliquots were frozen at $-20^{\circ} \mathrm{C}$ for later analysis. Samples were collected under the Animal (Scientific Procedures) Act, 1986, Home Office Pro-

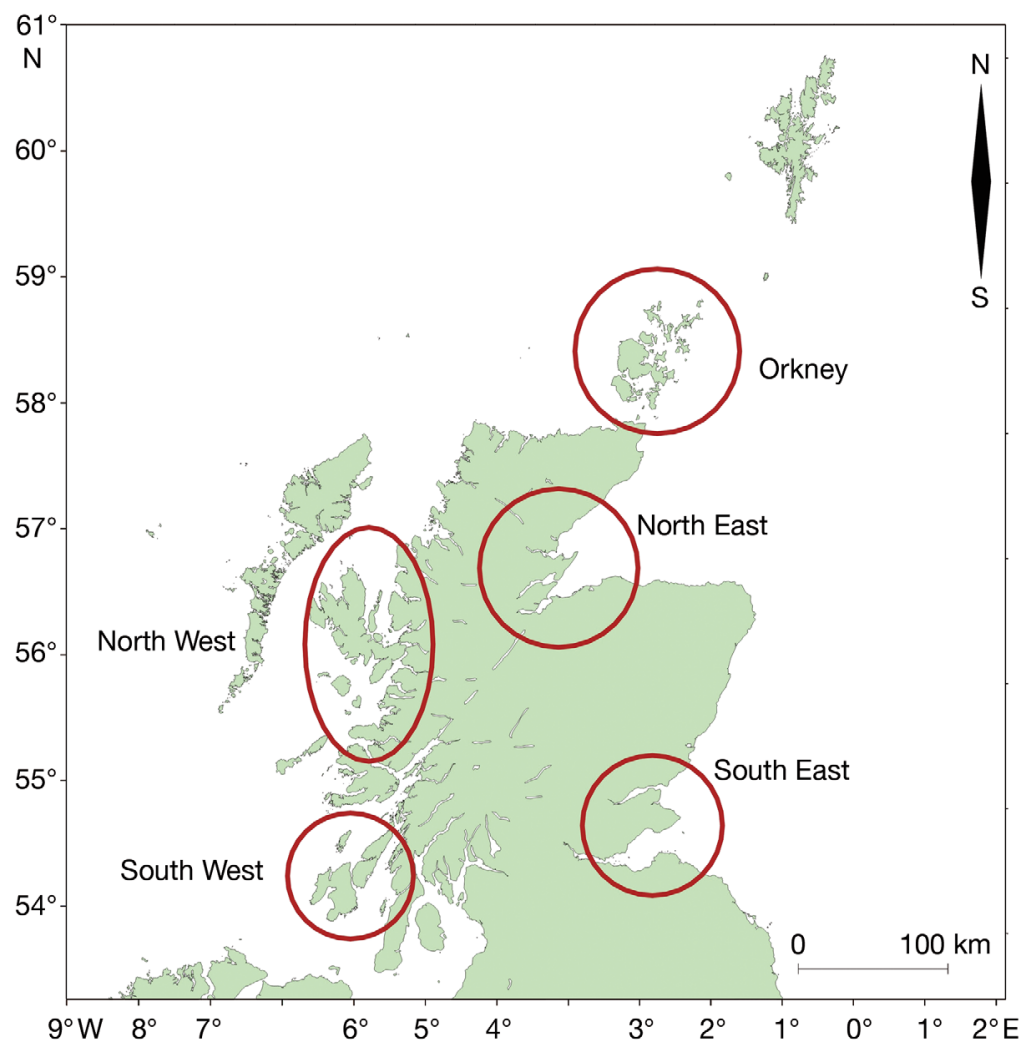

Fig. 1. Sampling regions of live-captured harbour seals across Scotland between 1997 and 2012 by the Sea Mammal Research Unit. Serum samples were grouped into 5 main regions across Scotland as indicated by the circles on the map. Over this time period, the populations along the west coast, marked as 'North West' and 'South West' were stable while the populations in 'Orkney', the 'North East' and the 'South East' underwent precipitous declines (SCOS 2012) ject and Personal Licences issued to the Sea Mammal Research Unit.

\section{Serological methods}

In a preliminary trial, the Rose Bengal plate agglutination test (RBT) was used to test stored serum samples for the presence of Brucella antibodies. Serum samples were tested with the Micropath Rose Bengal kit against the $B$. abortus antigen (Omega Diagnostics) following the kit instructions. Samples were either classed as positive or negative based on visually discernible agglutination of antigens. A positive and a negative control supplied by the kit were used for each set of 4 serum samples tested simultaneously.

Following the completion of the Rose Bengal trials with the successful detection of antibodies, the variation in seroprevalence, i.e. the proportion of animals with antibody levels higher than a background threshold level set for terrestrial mammals, as well as the absolute antibody levels in the samples, were investigated using a competitive ELISA (cELISA). Here, polystyrene microtitre plates were coated with Brucella melitensis lipopolysaccharide (LPS) antigen. Both positive (positive serum from an experimentally infected goat with $B$. melitensis) and negative controls (no sera) were tested. Serum and a peroxidase-labelled monoclonal antibody (BM40 from a locally held hybridoma) were added to the plates and incubated for 30 min at room temperature. The plate was then washed, and chromogen and substrate were added and incubated for a further $15 \mathrm{~min}$ at room temperature, shaking at $160 \mathrm{rpm}$. The plates were read at an optical density (OD) of $450 \mathrm{~nm}$. The mean OD of duplicate wells was expressed as a percentage of antibodies binding to the plate. Test samples with an OD of less than $60 \%$ of the conjugate-only control (no sera added) were recorded as positive. This cut-off threshold was established based on serology results from terrestrial mammals (Perrett et al. 2010). As such, a weak reaction, indicative of low antibody levels, was considered to be between 30 and $60 \%$ antibody binding, while a strong reac- 
Table 1. Serological samples collected from harbour seals across the 5 sampling regions of Scotland and over 12 yr broken down into 4 time periods. Samples are grouped by sex and age class. A total of 306 adults, 15 juveniles and 22 pups were sampled

\begin{tabular}{|c|c|c|c|c|c|c|c|}
\hline $\begin{array}{l}\text { Sampling } \\
\text { period }\end{array}$ & Sex & $\begin{array}{l}\text { Age } \\
\text { class }\end{array}$ & $\begin{array}{l}\text { Serolog } \\
\text { North } \\
\text { East }\end{array}$ & $\begin{array}{c}\text { ical sam } \\
\text { North } \\
\text { West }\end{array}$ & $\begin{array}{l}\text { Orknes coll } \\
\text { Orkney }\end{array}$ & $\begin{array}{c}\text { ected by } \\
\text { South } \\
\text { East }\end{array}$ & $\begin{array}{l}\text { region } \\
\text { South } \\
\text { West }\end{array}$ \\
\hline \multirow[t]{6}{*}{ 1997-2000 } & \multirow[t]{3}{*}{ Male } & Adults & - & - & - & 37 & - \\
\hline & & Juveniles & - & - & - & 1 & - \\
\hline & & Pups & - & - & - & 3 & - \\
\hline & \multirow[t]{3}{*}{ Female } & Adults & - & - & - & 21 & - \\
\hline & & Juveniles & - & - & - & 1 & - \\
\hline & & Pups & - & - & - & - & - \\
\hline \multirow[t]{6}{*}{ 2001-2005 } & \multirow[t]{3}{*}{ Male } & Adults & 5 & - & 11 & 15 & 14 \\
\hline & & Juveniles & - & - & - & 1 & - \\
\hline & & Pups & - & - & - & - & - \\
\hline & \multirow[t]{3}{*}{ Female } & Adults & 10 & - & 12 & 9 & 4 \\
\hline & & Juveniles & 1 & - & - & 2 & 2 \\
\hline & & Pups & - & - & - & - & 1 \\
\hline \multirow[t]{6}{*}{ 2006-2008 } & \multirow[t]{3}{*}{ Male } & Adults & 3 & 1 & 10 & 16 & 8 \\
\hline & & Juveniles & - & - & - & - & 1 \\
\hline & & Pups & - & - & - & - & 5 \\
\hline & \multirow[t]{3}{*}{ Female } & Adults & 7 & 1 & 15 & 6 & 7 \\
\hline & & Juveniles & 1 & - & - & - & - \\
\hline & & Pups & 2 & - & 11 & - & - \\
\hline \multirow[t]{6}{*}{ 2009-2012 } & \multirow[t]{3}{*}{ Male } & Adults & 1 & 14 & 21 & 10 & 2 \\
\hline & & Juveniles & 1 & - & 1 & - & 1 \\
\hline & & Pups & - & - & - & - & - \\
\hline & \multirow[t]{3}{*}{ Female } & Adults & 6 & 11 & 20 & 1 & 8 \\
\hline & & Juveniles & 1 & - & - & - & 1 \\
\hline & & Pups & - & - & - & - & - \\
\hline
\end{tabular}

tion, indicative of high circulating antibody levels, was considered to be $<30 \%$.

\section{Statistical analysis of serological data}

All statistical analyses were performed using the statistical package R, version 3.1.2 (R Core Development Team 2014). Results were considered statistically significant at $\mathrm{p} \leq 0.05$. Two different statistical approaches were taken to investigate firstly, variation in the seroprevalence data, and secondly, variation in the antibody levels in the seropositive individuals.

For the seroprevalence data, generalised linear models (GLMs) with a binomial distribution were fitted to the seroprevalence data with individuals classed as seropositive (1) and seronegative (0) for the 2 tests separately. The $14 \mathrm{yr}$ of data were split into 4 time periods: 1997 to $2000(\mathrm{n}=63)$ represents the years before the start of the decline, and the years be- tween 2001 and 2012 were split into 3 periods with approximately equal numbers of samples in each to give the maximum statistical power for the analysis. These were 2001 to 2005 ( $\mathrm{n}=$ 87), 2006 to 2008 ( $\mathrm{n}=94$ ) and 2009 to 2012 ( $\mathrm{n}=99$ ). A global model including all explanatory variables of interest (region, sex, age class, time period and an interaction between region and time period) was generated, and backwards variable selection using the 'step' function in the 'car' library in R v.2.11.1 was performed to identify the combination of variables that best explained the variation in the data by producing the model with the lowest Akaike's information criterion (AIC) value.

In addition, variation in the levels of circulating Brucella antibodies were investigated in the seropositive individuals identified using the cELISA data. Antibody binding results of only the seropositive seals were modelled using a GLM with a gamma distribution and a log-link function to model the non-normal distribution of the antibody binding data, as most individuals had low circulating antibody levels while few were very high. Again, a global model with region, sex, age class, time and an interaction between region and time was generated and backwards variable selection using the 'step' function was used to identify the combination of variables that best explained the variation in the data.

\section{RESULTS}

\section{Brucella cultures}

Of the 150 animals examined bacteriologically between 1992 and 2013, Brucella was isolated from the tissues of 24 individuals (16\%). Details for 11 of these animals have been reported previously (Foster et al. 2002). None of the culture-positive animals showed any signs of pathological lesions associated with infection, and the cause of death was always associated with starvation, trauma or some other viral or bacterial infection, but not Brucella. Of the tissues cultured, the 2 that were the most commonly culturepositive were lung $(45.8 \%)$ and spleen $(41.7 \%)$, 
Table 2. Details of 24 Brucella culture-positive harbour seals. The last 2 digits of the reference number indicate the year of stranding. ( $\left.{ }^{*}\right)$ Indicates individuals that were culture-positive but seronegative. MLN: mesenteric lymph node; IILN: internal iliac lymph node; EILN: external iliac lymph node; GLN: gastric lymph node; ManLN: mandibular lymph node; HLN: hepatic lymph node; TLN: thoracic lymph node; CLRN: colorectal lymph node; SI: small intestine

\begin{tabular}{|lll|}
\hline Reference no. & Positive cultures & Negative cultures \\
\hline M2357/93 & Spleen & Lung, liver \\
M2466/93 & Spleen & Lung, MLN \\
M2533/93 & Spleen & MLN, SI \\
M292/94* & Spleen & Testes, MLN, SI \\
M336/94* & IILN & Spleen, MLN \\
M339/94 & GLN & Spleen, IILN \\
M972/94 & EILN, manLN & Spleen, MLN \\
M490/95 & EILN, HLN, IILN, TLN & Lung, spleen, brain, CRLN, GLN, manLN, blood, SI \\
M514/96 & Lung & \\
M445/99 & Lung & Liver, spleen, kidney, brain, MLN, blood, SI \\
M13/01 & Lung & Liver, spleen, kidney, blood \\
M250/02 & Lung, liver, spleen, kidney, MLN, blood & Brain, SI \\
M305/02 & Spleen & Lung, liver, kidney, brain, MLN, cellulitis, SI \\
M342/02 & MLN & Lung, liver, spleen, kidney, brain, blood \\
M374/02 & Lung, liver, spleen, kidney & Brain, MLN \\
M449/02 & Lung & \\
M599/02 & MLN & Lung, liver, spleen, kidney \\
M43/09 & Lung, liver, spleen, kidney, MLN, SI & \\
M91/10 & Lung, brain & Liver, spleen, kidney, MLN \\
M228/10 & Pancreas & Lung, liver, spleen, kidney, brain, MLN, SI \\
M244/10 & Lung, liver, spleen, brain, MLN, SI & Kidney \\
M273/10 & Lung, MLN & Liver, spleen, kidney, brain, pre-Scapular LN, SI \\
M341/11 & Lung, spleen, MLN, SI & Liver, kidney, brain, abscess \\
M337/13 & Kidney, brain & Lung, liver, spleen \\
\hline
\end{tabular}

although not all tissues were sampled consistently across individuals (Table 2). MLVA-16 analysis identified isolates as B. pinnipedialis belonging to 1 of 2 sequence types: ST 24 or ST 25. Serum was sampled from 12 of these culture-positive seals, 2 of which were seronegative and were sampled from healthy animals that had been shot (Table 2).

\section{Serology}

Test performance

The RBT trials were able to detect antibodies in the archived serum samples, and results showed that across all study sites over the whole sampling period, the prevalence of Brucella antibodies was $15.9 \%$. However, the cELISA results showed a higher overall seroprevalence of $25.4 \%$. The prevalence across all age and sex classes, as well as across regions and over time was lower for the RBT results compared to the cELISA results (Table 3 ).

All of the samples that were positive using the RBT were also classed as positive using the cELISA. These samples had the lowest antibody binding indi-
Table 3. Comparison of the prevalence (\% of seropositive harbor seals) using the Rose Bengal plate agglutination test (RBT) and the competitive ELISA (cELISA). The ELISA results indicate a higher overall prevalence of Brucella antibodies in harbour seals than the RBT results

\begin{tabular}{|lrrc|}
\hline \multirow{2}{*}{ Variable } & $\mathrm{n}$ & \multicolumn{2}{c|}{ \% of seropositive animals } \\
& & RBT & cELISA \\
\hline Scotland & 343 & 15.9 & 25.4 \\
North East & 38 & 28.6 & 28.9 \\
North West & 27 & 14.8 & 33.3 \\
Orkney & 101 & 12.9 & 28.7 \\
South East & 123 & 19.8 & 20.3 \\
South West & 54 & 3.9 & 24.1 \\
Males & 183 & 14.5 & 25.7 \\
Females & 160 & 17.4 & 24.4 \\
Adults & 306 & 14.5 & 25.2 \\
Juveniles & 15 & 60.0 & 53.3 \\
Pups & 22 & 4.5 & 9.09 \\
1997-2000 & 63 & 12.3 & 22.2 \\
2001-2005 & 87 & 24.7 & 26.4 \\
2006-2008 & 94 & 12.0 & 18.1 \\
2009-2012 & 99 & 13.7 & 33.3 \\
\hline
\end{tabular}

cating the highest circulating Brucella antibodies. Specifically, the mean antibody binding of the samples classed as positive by the RBT was $45.0 \pm 0.06 \%$, 
while those classed as negative had a mean antibody binding of $74.0 \pm 0.02 \%$ (2-sample $t$-test; $t=8.79$, df $=$ $51.54, \mathrm{p}<0.0001)$. Therefore, it seems that the RBT is only able to detect high antibody levels in the serum samples and is the least sensitive of the 2 serological methods tested. As a result, the RBT results may have underestimated the prevalence of Brucella antibodies in these harbour seals (Table 3 ).

\section{Seroprevalence}

Using the cELISA seroprevalence data where individuals were classed as either seropositive or seronegative, the best binomial GLM after backwards variable selection included only age class as an important explanatory variable. Juveniles had a significantly higher seroprevalence than adults and pups ( $p$-values $<0.025$ ), while adults and pups were not significantly different from each other $(p=0.11)$. There were no significant changes in prevalence over time or between regions, and there were equal numbers of seropositive males and females.

\section{Antibody levels}

Variation in the levels of circulating Brucella antibodies were investigated in the seropositive individuals. Backwards variable selection of the GLM using the cELISA antibody binding results of only the

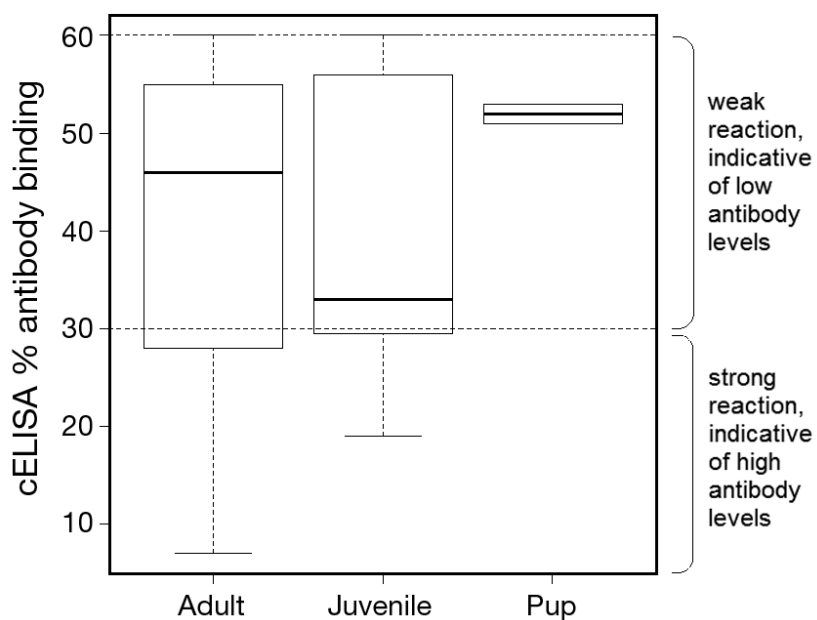

Fig. 2. Competitive ELISA (cELISA) antibody binding of the seropositive harbour seals by age class. Lines in the boxes represent the median values; box edges are the 25th and 75th percentiles. Low antibody binding indicates high levels of circulating Brucella antibodies in the seals. Pups had lower circulating antibody levels than both adults and juveniles seropositive seals revealed that age class and an interaction between region and time period were retained in the final model with significant effects. Pups had near-significant higher antibody binding than both adults and juveniles (both p-values $<0.07$ ), indicating the lowest circulating antibodies in these seropositive individuals (Fig. 2). There was no difference between the circulating antibody levels in juveniles and adults (Fig. 2). The interaction between region and time revealed that there were different patterns in circulating antibody levels in the seropositive seals between regions over the $14 \mathrm{yr}$ sampling period. The highest average circulating Brucella antibody levels (shown as the lowest \% antibody binding in Fig. 3) were measured in the 2001 to 2005 time period in the South West, and these then decreased over the following years $(p=0.035)$. All areas showed a decrease followed by an increase again over the whole time frame, with the exception of Orkney, which showed a sustained decrease in circulating antibodies between 2001 and 2012 (Fig. 3), and the North West, where seropositive individuals were only recorded in the final time period, but this is likely a reflection of very limited sampling before 2009 (Table 1) rather than a recent introduction of the bacteria to the area. Males and females had similar antibody levels.

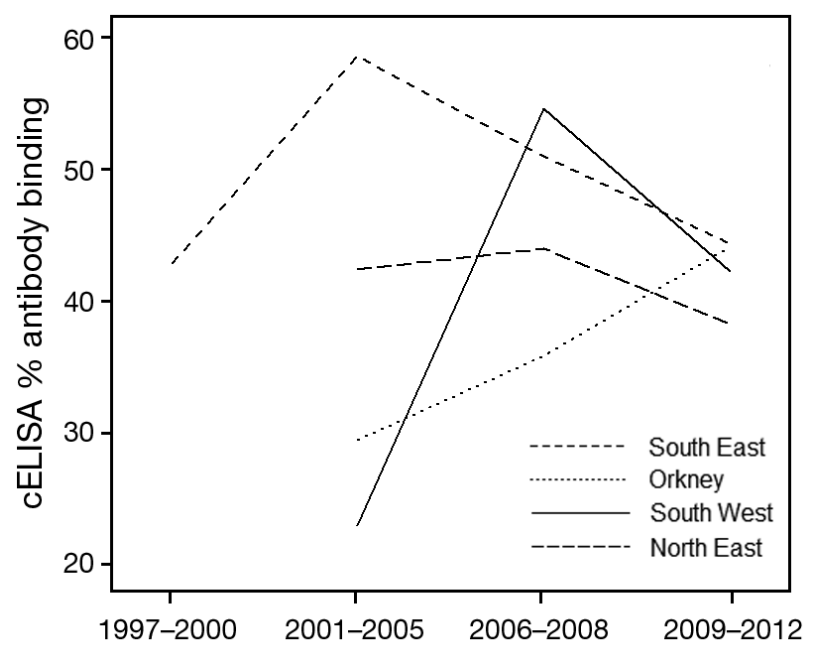

Fig. 3. Interaction plot of the competitive ELISA (cELISA) \% antibody binding over time for each sampling region showing variation in seropositive harbour seal individuals. Low antibody binding indicates high levels of circulating Brucella antibodies in the seals. The North West sampling region is not included here as seropositive animals were only identified in this area between 2009 and 2012. With the exception of Orkney, the other sampling regions showed a decrease in the circulating levels of Brucella antibodies,

followed by an increased again over this time period 


\section{DISCUSSION}

Brucella species were isolated from $16 \%$ of the dead stranded animals tested, but there were no signs of Brucella-specific pathological lesions associated with infection in these 24 animals. They all appear to have died of other causes, although it is possible that Brucella acted as a secondary infection in these cases. The results presented here therefore suggest that harbour seals can be infected by Brucella, likely $B$. pinnipedialis, without evidence of associated disease. B. pinnipedialis has also been cultured from apparently healthy tissues of a number of other pinniped species, including grey seals Halichoerus grypus (Foster et al. 2002, Prenger-Berninghoff et al. 2008), hooded seals Cystophora cristata (Foster et al. 2002, Tryland et al. 2005), ringed seals Pusa hispida (Forbes et al. 2000) and harp seals Pagophilus groenlandicus (Forbes et al. 2000). At present, there is only limited evidence of Brucella infection causing disease in any species of phocid seal (Jauniaux et al. 2013), although Brucella isolation was suggested as a possible cause of abortion in an otariid species, the California sea lion Zalophus californianus, with recovery of Brucella from the placenta and stomach contents of an aborted foetus (Goldstein et al. 2009). Extensive typing of a large number of marine mammal Brucella strains in a recent study, however, found the Californian sea lion isolates to be similar to $B$. ceti recovered from bottlenose dolphins in the USA and that $B$. pinnipedialis isolates from harbour seals in the USA were found to be closely related to Scottish strains (A. M. Whatmore et al. unpubl. data).

Animal experimentation in cattle with a Brucella isolate recovered from a Pacific harbour seal Phoca vitulina richardsii resulted in seroconversion and abortion in 2 of 3 pregnant animals, suggesting that some strains of $B$. pinnipedialis may have abortifacient potential (Rhyan et al. 2009). However, there has been no evidence in pinnipeds of disease due to $B$. pinnipedialis as has been seen with $B$. ceti infection in dolphins and porpoises where chronic disease with significant clinical and pathological signs including male infertility, neurobrucellosis, cardiopathies, bone and skin lesions and live strandings have been documented (Guzmán-Verri et al. 2012). While no evidence of disease has been reported in pinnipeds, detecting abortions in wild populations is very difficult, especially if the occurrence remains constant over time and there is limited data on pupping success, as is the case for the populations sampled here. The ability to detect abortions and monitor pupping success in different populations is therefore needed in order to determine that $B$. pinnipedialis does not cause disease in these seals.

Similar to this study, Brucella antibodies have been detected in sera from a number of marine mammal species using Rose Bengal tests (Tryland et al. 1999, 2005, Retamal et al. 2000, Hernández-Mora et al. 2008, Jensen et al. 2013), and using both indirect ELISA (iELISA) and cELISAs primarily designed for ruminants (Tryland et al. 1999, Nielsen et al. 2001, Van Bressem et al. 2001, Tachibana et al. 2006, Roe et al. 2010, Lynch et al. 2011, Jensen et al. 2013, Nymo et al. 2013a). Here, differences in the prevalence estimates obtained from the RBT and the cELISA results highlight the need to consider test performance when conducting serological studies. It seems that the RBT is only able to detect antibodies when at higher levels, and as such, seropositive samples with low levels of antibody are not recognised.

Our results suggest that the cELISA appears to be a more sensitive test than RBT and is thus able to distinguish between seronegative samples and samples with low antibody levels. The cELISA results were therefore chosen for further analysis over the RBT results as this is thought to be a more robust and objective test. However, when detecting Brucella antibodies using serological methods, serological cross-reactions and false positives are potentially a major problem, and may contribute to the higher seroprevalence seen in the cELISA results. It is thought that in cattle most problems caused by crossreactivity are the result of antibodies produced through the immune response of the animal to other microorganisms sharing similar structural characteristics with the O-polysaccharide of Brucella species (Corbel 1985). We cannot rule out the possibility that other cross-reacting bacteria could affect these results. In cattle, it is thought that the cELISA is a more appropriate serological test than the iELISA as it is better able to distinguish between antibodies to Brucella species and antibodies to other cross-reacting Gram-negative bacteria (Nielsen 1990, Samartino et al. 1999). In 2 studies on Australian fur seals (Lynch et al. 2011) and Hawaiian monk seals Monachus schauinslandi (Nielsen et al. 2005), it was concluded that the iELISA was an unreliable test for the identification of seropositive individuals. Thus, based on this previous evidence, the cELISA was chosen here as an appropriate assay as it is more conservative than an iELISA with a reduced chance of false positives.

The cELISA results indicate that approximately $25 \%$ of the seals sampled had antibodies to Brucella. 
This is within the range of previous studies on harbour seal populations in the North Atlantic, where prevalence ranged between $3.1 \%(n=96)$ in the St Lawrence Estuary, $14 \%(\mathrm{n}=21)$ (Maratea et al. $2003)$ and $50 \%(n=8)$ off the Atlantic coast of the United States (Nielsen et al. 2001). Serology testing of 300 Scottish harbour seals prior to 2002 found 147 $(49 \%)$ to be positive (Foster et al. 2002). As there appears to have been no change in antibody prevalence over this $14 \mathrm{yr}$ sampling period, or between regions, these data suggest that Brucella may be endemic in Scottish harbour seals, and exposure to the bacteria seems to have remained constant over the study period. For endemicity to occur, a high and regular rate of transmission of the bacteria is required within a population.

The transmission of Brucella in marine mammals is poorly understood as there is little evidence to support any particular route of infection in these species. It is likely that the routes of transmission are similar to those of terrestrial mammals, whereby transmission occurs through exposure to infected placenta, birth fluids and vaginal secretions as well as by venereal spread (Young 2006). As Brucella has been isolated from the reproductive organs of several cetacean species (Miller et al. 1999, Foster et al. 2002, González-Barrientos et al. 2010), and from an aborted foetus of a captive bottlenose dolphin (Ewalt et al. 1994), the most likely mode of transmission of $B$. ceti appears to be through sexual intercourse, vertical transmission from mother to foetus, maternal feeding and contact with aborted foetuses and placental tissues (Guzmán-Verri et al. 2012). The transmission between pinnipeds is even less well understood, but it could be similar to cetaceans. However, transmission may also occur through contact with infected individuals in gregarious species that haul out together in large groups. Brucella was cultured from the faeces of a seropositive juvenile harbour seal in captivity (Gaydos et al. 2005), suggesting that some Brucella-positive seals are actively shedding the bacteria. In addition, B. pinnipedialis was cultured or detected by PCR in harbour seal salivary gland secretions, lungs, urinary bladder and faeces (Lambourn et al. 2013), suggesting that seals could be exposed to the bacterium via exposure to oral secretions, urine or faeces on haul-outs. Brucella has also been isolated from subcutaneous lesions in cetaceans (Foster et al. 1996, 2002), so the potential for direct contact with similarly infected skin lesions, should they occur, in pinnipeds that haul out together may present another mode of transfer of the bacteria, although such lesions have not been reported to date.
Together, this could make harbour seals more at risk of bacterial transfer at particular times during their life cycle when they haul-out in larger numbers during the breeding season and during the moult. Thus, the requirements of a high and regular rate of transmission of the bacteria for endemicity to occur could be met for harbour seals.

There was no regional variation in seroprevalence across Scotland, indicating that seals in the declining populations in Orkney and along the East coast have similar proportions of seropositive seals to the stable populations along the West coast. In addition, there has been no change in prevalence over time, even in declining populations, and none of the seals sampled in this study showed any overt signs of ill health. These results further support the hypothesis that they may be infected by a strain of the bacteria that appears to be having little effect on their health. Other pinniped species have also been shown to be seropositive and yet remain apparently healthy and asymptomatic (Nielsen et al. 1996, 2005, Retamal et al. 2000, Nymo et al. 2011). Together, these results indicate that the bacteria may only cause a mild and transient infection, and $B$. pinnipedialis is most likely not a major cause of the harbour seal decline in Scotland. Other potential causes of the declines should therefore continue to be investigated.

Juveniles showed the highest overall prevalence of the 3 age classes. It has been reported that the higher incidence in juveniles may be a result of recent exposure to the pathogen due to a change to a prey-based diet after they are weaned (Lynch et al. 2011, Nymo et al. 2013b). Lungworms carrying Brucella in fish prey species may be a means by which marine mammals become infected with the bacterium, as was suggested when Brucella was isolated from the lungworms in a harbour porpoise Phocoena phocoena (Dawson et al. 2008). Brucella species have also have also been found by immunohistochemical staining in the uterus and the intestinal lumen of female Parafilaroides lungworms from a Pacific harbour seal (Garner et al. 1997), and it was postulated that, based on the life cycle of the parasite, the larvae migrate through the respiratory tract and are then swallowed. From there, they pass through the digestive tract and out into the environment in the faeces, where they are taken up by fish and ultimately by the seal. The parasitic larvae are released into the gastrointestinal tract of the animal, and when they mature into adults, they migrate to the lungs and continue the life cycle (Howard et al. 1983). It may also be significant that lung was the body tissue with the highest isolation rate from the 24 harbour seals that were positive by Brucella culture. 
As such, the high levels of antibodies in seropositive juveniles may suggest a more recent exposure to Brucella as they first start to eat fish containing the infected parasites, but it is not necessarily indicative of an active infection. The seropositive adults have high antibody levels which may be indicative of both previous and regular exposure to the bacteria.

The finding that there were lower levels of Brucella antibodies in the seropositive pups compared to both seropositive adults and juveniles is surprising. It would be expected that passively transferred maternal antibodies would be present in pups, as they are found in the offspring of antibody-positive mothers in terrestrial species (Ray et al. 1988, Thakur et al. 2002, Rhyan et al. 2009). However, a lower seroprevalence was seen in Australian fur seal (Lynch et al. 2011), Hawaiian monk seal (Aguirre et al. 2007), hooded seal (Nymo et al. 2013b) and Alaskan harbour seal pups (Zarnke et al. 2006) compared to both adults and juveniles. In these studies, it was concluded that pups may have had maternal antibodies at titres lower than the threshold of detection used in their serological tests. These data support the theory that pups likely have low levels of maternal antibodies and that they may not be exposed to infection until a later stage post-weaning (Lynch et al. 2011). These findings further highlight the need for investigations into the timing of first exposure to Brucella and seroconversion as well as the development of specific thresholds of detection for antibodies to marine mammal strains of Brucella in various serological tests.

While the overall proportion of positive seals did not change across the different sampling regions over time, there were varying patterns of high and low antibody levels measured in the seropositive seals. Higher antibody levels were not recorded in the declining populations, however, and there were no populations with consistently higher or lower antibody levels. The presence of antibodies does not necessarily suggest that the animals had a current or active infection at the time of sampling. The variation over time seen here between populations likely reflects cycles of infection followed by clearance in infected individuals that do not show any clinical signs of the disease. While the apparently high exposure rates of Scottish harbour seals to Brucella appear not to be having a negative impact on their populations, such levels may have important implications for cross-species infections between humans and domestic livestock, where infections may lead to disease. Currently, a total of 53 marine mammal species worldwide have been shown to be seropositive for Brucella antibodies, and 20 of these species have been positive for $B$. ceti or $B$ pinni- pedialis by culture or PCR assays (Hernández-Mora et al. 2013, Foster et al. 2015). The high seroprevalence seen here in all populations across Scotland suggests that wildlife professionals working with live seals could be exposed to the bacterium, and care should be taken when handling the animals and working with samples. To date, there have been 4 documented cases of humans infected with $B$. ceti (Brew et al. 1999, Sohn et al. 2003, McDonald et al. 2006), demonstrating the zoonotic potential of that species, but human infections with $B$. pinnipedialis have not been documented.

In conclusion, over one-quarter of Scottish harbour seals have detectable levels of antibodies to Brucella which may indicate endemicity in these populations, possibly to a strain of the pathogen that has little effect on the health of individuals. These prevalence rates do not appear to explain the declines in Orkney and along the East coast as the prevalence in these areas is the same as in populations along the West coast that remain stable. The causes of the decline are likely to vary between regions and are probably due to a combination of factors, but Brucella infection does not appear to be one of them, based on our findings and comparison with seroprevalence rates for Scottish harbour seals before 2002 (Foster et al. 2002). Despite the routine use of the serological tests used here in many assessments of exposure to Brucella species, further validation of the tests for marine mammals is needed, and the discrepancies between the 2 test types here highlight the need for careful interpretation of the results.

Acknowledgements. The authors thank all the staff and students at the Sea Mammal Research Unit who were involved in the live capture-release fieldwork, with particular thanks to Simon Moss and Matthew Bivins. We also acknowledge the contributions of Harry Ross, Tony Patterson and Bob Reid for the post mortems of seals and provision of tissues for culture. Finally we acknowledge the NERC National Capability Funding grant number SMRU 10001 for the funding.

\section{LITERATURE CITED}

Aguirre AA, Keefe TJ, Reif JS, Kashinsky L and others (2007) Infectious disease monitoring of the Endangered Hawaiian monk seal. J Wildl Dis 43:229-241

Alba P, Terracciano G, Franco A, Lorenzetti S and others (2013) The presence of Brucella ceti ST26 in a striped dolphin (Stenella coeruleoalba) with meningoencephalitis from the Mediterranean Sea. Vet Microbiol 164: 158-163

Bolt HE, Harvey PV, Mandleberg L, Foote AD (2009) Occurrence of killer whales in Scottish inshore waters: temporal and spatial patterns relative to the distribution of 
declining harbour seal populations. Aquat Conserv 19: 671-675

Brew SD, Perrett LL, Stack JA, MacMillan AP, Staunton NJ (1999) Human exposure to Brucella recovered from a sea mammal. Vet Rec 144:483

Brownlow A, Onoufriou J, Bishop A, Davison N, Thompson D (2016) Corkscrew seals: grey seal (Halichoerus grypus) infanticide and cannibalism may indicate the cause of spiral lacerations in seals. PLOS ONE 11:e0156464

Corbel MJ (1985) Recent advances in the study of Brucella antigens and their serological cross-reactions. Vet Bull 55:927-942

Dagleish MP, Barley J, Finlayson J, Reid RJ, Foster G (2008) Brucella ceti associated pathology in the testicle of a harbour porpoise (Phocoena phocoena). J Comp Pathol 139: 54-59

Dawson CE, Perrett LL, Stubberfield EJ, Stack JA and others (2008) Isolation and characterisation of Brucella from the lungworms of a harbour porpoise (Phocoena phocoena). J Wildl Dis 44:237-246

Ewalt DR, Payeur JB, Martin BM, Cummins DR, Miller WG (1994) Characteristics of a Brucella species from a bottlenose dolphin (Tursiops truncatus). J Vet Diagn Invest 6: $448-452$

Forbes LB, Nielsen O, Measures L, Ewalt DR (2000) Brucellosis in ringed seals and harp seals from Canada. J Wildl Dis 36:595-598

Foster G, Jahans KL, Reid RJ, Ross HM (1996) Isolation of Brucella species from cetaceans, seals and an otter. Vet Rec 138:583-586

Foster G, MacMillan AP, Godfroid J, Howie F and others (2002) A review of Brucella sp. infection of sea mammals with particular emphasis on isolates from Scotland. Vet Microbiol 90:563-580

Foster G, Osterman BS, Godfroid J, Jacques I, Cloeckaert A (2007) Brucella ceti sp. nov. and Brucella pinnipedialis sp. nov. for Brucella strains with cetaceans and seals as their preferred hosts. Int J Syst Evol Microbiol 57: 2688-2693

Foster G, Whatmore AM, Dagleish MP, Baily JL and others (2015) Isolation of Brucella ceti from a long-finned pilot whale (Globicephala melas) and a Sowerby's beaked whale (Mesoloden bidens). J Wildl Dis 51:868-871

Garner MM, Lambourn DM, Jeffries SJ, Hall PB and others (1997) Evidence of Brucella infection in Parafilaroides lungworms in a Pacific harbor seal (Phoca vitulina richardsi). J Vet Diagn Invest 9:298-303

Garofolo G, Zilli K, Troiano P, Petrella A and others (2014) Brucella ceti from two striped dolphins stranded on the Apulia coastline, Italy. J Med Microbiol 63:325-329

Gaydos JK, Norman SA, Lambourn D, Jeffries S and others (2005) Should harbour seals with antibodies to Brucella be rehabilitated? Presentation at the $36^{\text {th }}$ annual conference of the International Association of Aquatic Animal Medicine, 14-19 May 2005, Seward, AK

Goldstein T, Zabka TS, Delong RL, Wheeler EA and others (2009) The role of domoic acid in abortion and premature parturition of Californian sea lions (Zalophus californianus) on San Miguel Island. J Wildl Dis 45:91-108

*González L, Patterson IA, Reid RJ, Foster G and others (2002) Chronic meningoencephalitis associated with Brucella sp. infection in live-stranded striped dolphins (Stenella coeruleoalba). J Comp Pathol 126:147-152

González-Barrientos R, Morales JA, Hernández-Mora G, Barquero-Calvo E, Guzmán-Verri C, Chaves-Olarte E,
Moreno E (2010) Pathology of striped dolphins (Stenella coeruleoalba) infected with Brucella ceti. J Comp Pathol 142:347-352

* Guzmán-Verri C, González-Barrientos R, Hernández-Mora G, Morales JA, Baquero-Calvo E, Chaves-Olarte E, Moreno E (2012) Brucella ceti and brucellosis in cetaceans. Front Cell Infect Microbiol 2:3

Hall AJ, Frame E (2010) Evidence of domoic acid exposure in harbour seals from Scotland: a potential factor in the decline in abundance? Harmful Algae 9:489-493

Hanson N, Thompson D, Duck C, Baxter J, Lonergan M (2017) Harbour seal (Phoca vitulina) abundance within the Firth of Tay and Eden estuary, Scotland: recent trends and extrapolation to extinction. Aquat Conserv 27:268-281

*Hernández-Mora G, González-Barrientos R, Morales JA, Chaves-Olarte E and others (2008) Neurobrucellosis in stranded dolphins, Costa Rica. Emerg Infect Dis 14: 1430-1433

*Hernández-Mora G, Palacios-Alfaro JD, González-Barrientos R (2013) Wildlife reservoirs of brucellosis: Brucella in aquatic environments. Rev Sci Tech 32:89-103

Howard EB, Britt JO, Matsumoto G (1983) Parasitic diseases. In: Howard EB (ed) Pathobiology of marine mammal diseases. CRC Press, Boca Raton, FL, p 128-213

*Hueffer K, Gende SM, O'Hara TM (2013) Assay dependence of Brucella antibody prevalence in a declining Alaskan harbor seal (Phoca vitulina) population. Acta Vet Scand $55: 2$

Jauniaux TP, Brenez C, Frentin D, Godfroid J and others (2010) Brucella ceti infection in harbor porpoise (Phocoena phocoena). Emerg Infect Dis 16:1966-1968

Jauniaux T, Didier M, Fretin D, Godfroid J and others (2013) Brucellosis in two seal pups. In: de Mar E (ed) Abstract book: $27^{\text {th }}$ annual conference of the European Cetacean Society, 8-10 April 2013, Setubal. ECS, Setubal, p 136

Jensen SK, Nymo IH, Forcada J, Hall AJ, Godfroid J (2013) Brucella antibody seroprevalence in Antarctic seals (Arctocephalus gazella, Leptonychotes weddellii and Mirounga leonina). Dis Aquat Org 105:175-181

Kambourn DM, Garner M, Ewalt D, Raverty S and others (2013) Brucella pinnipedialis infections in Pacific harbor seals (Phoca vitulina richardsi) from Washington State, USA. J Wildl Dis 49:802-815

* Lonergan M, Duck CD, Thompson D, Mackey BL, Cunningham L, Boyd IL (2007) Using sparse survey data to investigate the declining abundance of British harbour seals. J Zool (Lond) 271:261-269

* Lynch M, Duignan PJ, Taylor T, Nielsen O, Kirkwood R, Gibbens J, Arnould JPY (2011) Epizootiology of Brucella infection in Australian fur seals. J Wildl Dis 47:352-363

Maquart M, Le Flèche $P$, Foster $G$, Tryland $M$ and others (2009) MLVA-16 typing of 295 marine mammal Brucella isolates from different animal and geographic origins identifies 7 major groups within Brucella ceti and Brucella pinnipedialis. BMC Microbiol 9:145

Maratea J, Ewalt D, Frasca S, Dunn JL and others (2003) Evidence of Brucella sp. infection in marine mammals stranded along the coast of southern New England. J Zoo Wildl Med 34:256-261

McDonald WL, Jamaludin R, Mackereth G, Hansen M and others (2006) Characterization of a Brucella sp. strain as a marine-mammal type despite isolation from a patient with spinal osteomyelitis in New Zealand. J Clin Microbiol 44:4363-4370 
Miller WG, Adams LG, Ficht TA, Cheville NF and others (1999) Brucella-induced abortions and infection in bottlenose dolphins (Tursiops truncatus). J Zoo Wildl Med 30:100-110

Nielsen K (1990) The serological response of cattle immunized with Yersinia enterocolitica O:9 or O:16 to Yersinia and Brucella abortus antigens in enzyme immunoassays. Vet Immunol Immunopathol 24:373-382

* Nielsen O, Nielsen K, Stewart REA (1996) Serologic evidence of Brucella spp. exposure in Atlantic walruses (Odobenus rosmarus rosmarus) and ringed seals (Phoca hispida) of Arctic Canada. Arctic 49:383-386

Nielsen O, Stewart REA, Nielsen K, Measures L, Duignan PJ (2001) Serological survey of Brucella spp. antibodies in some marine mammals of North America. J Wildl Dis 37: 89-100

Nielsen O, Nielsen K, Braun R, Kelly L (2005) A comparison of four serologic assays in screening for Brucella exposure in Hawaiian monk seals. J Wildl Dis 41:126-133

Nymo IH, Tryland M, Godfroid J (2011) A review of Brucella infection in marine mammals, with special emphasis on Brucella pinnipedialis in the hooded seal (Cystophora cristata). Vet Res 42:93

Nymo IH, Godfroid J, Åsbakk K, Larsen AK, das Neves CG, Rødven R, Tryland M (2013a) A protein A/G indirect enzyme-linked immunosorbent assay for the detection of anti-Brucella antibodies in Arctic wildlife. J Vet Diagn Invest 25:369-375

Nymo IH, Tryland M, Frie AK, Haug T, Foster G, Rødven R, Godfroid J (2013b) Age-dependent prevalence of antiBrucella antibodies in hooded seals Cystophora cristata. Dis Aquat Org 106:187-196

Perrett LL, McGiven JA, Brew S, Stack JA (2010) Evaluation of competitive ELISA for detection of Brucella infection in domestic animals. Croat Med J 51:314-319

Prenger-Berninghoff E, Siebert U, Stede M, König A, Weiß R, Baljer G (2008) Incidence of Brucella species in marine mammals of the German North Sea. Dis Aquat Org 81: 65-71

R Core Development Team (2014) R: a language and environment for statistical computing. R Foundation for Statistical Computing, Vienna. www.R-project.org/

Ray WC, Brown RR, Stringfellow DA, Schnurrenberger PR, Scanlan CM, Swann AI (1988) Bovine brucellosis: an investigation of latency in progeny of culture-positive cows. J Am Vet Med Assoc 192:182-186

Retamal P, Abalos P, Blank O, Torres D (2000) Detection of anti-Brucella antibodies in pinnipeds from the Antarctic territory. Vet Rec 146:166-167

* Rhyan JC, Aune K, Roffe T, Ewalt D and others (2009) Pathogenesis and epidemiology of brucellosis in Yellowstone bison: serologic and culture results from females and their progeny. J Wildl Dis 45:729-739

Roe WD, Rogers LE, Gartrell BD, Chilvers BL, Duignan PJ (2010) Serologic evaluation of New Zealand sea lions for exposure to Brucella and Leptospira spp. J Wildl Dis 46: 1295-1299

Ross HM, Foster G, Reid RJ, Jahans KL, MacMillan AP (1994) Brucella species infection in sea-mammals. Vet Rec 134:359

Ross HM, Jahans KL, MacMillan AP, Reid RJ, Thompson
PM, Foster G (1996) Brucella species infection in North Sea seal and cetacean populations. Vet Rec 138:647-648

* Samartino L, Gall D, Gregoret R, Nielsen K (1999) Validation of enzyme-linked immunosorbent assays for the diagnosis of bovine brucellosis. Vet Microbiol 70:193-200

SCOS (Special Committee on Seals) (2012) Scientific advice on matters related to the management of seal populations: 2012. SCOS Main Advice 2012. Sea Mammal Research Unit, University of St Andrews

* Seleem MN, Boyle SM, Sriranganathan N (2010) Brucellosis: a re-emerging zoonosis. Vet Microbiol 140:392-398

Siebert U, Rademaker M, Ulrich SA, Wohlsein P, Ronnenberg K, Prenger-Berninghoff E (2017) Bacterial microbiota in harbour seals (Phoca vitulina) from the North Sea of Schleswig-Holstein, Gemany, around the time of morbillivrus and influenza epidemics. J Wildl Dis 53: 201-214

Sohn $\mathrm{AH}$, Probert WS, Glaser CA, Gupta N and others (2003) Human neurobrucellosis with intracerebral granuloma caused by a marine mammal Brucella spp. Emerg Infect Dis 9:485-488

* Tachibana M, Watanabe K, Kim S, Omata Y, Murata K, Hammond T, Watarai M (2006) Antibodies to Brucella spp. in Pacific bottlenose dolphins from the Solomon Islands. J Wildl Dis 42:412-414

* Thakur SD, Kumar R, Thapliyal DC (2002) Human brucellosis: review of an under-diagnosed animal transmitted disease. J Commun Dis 34:287-301

Thakur SD, Vaid RK, Panda AK, Saini Y (2012) Marine mammal brucellosis: a new dimension to an old zoonosis. Curr Sci 103:902-910

* Thompson PM, Mackey B, Barton TR, Duck C, Butler JRA (2007) Assessing the potential impact of salmon fisheries management on the conservation status of harbour seals (Phoca vitulina) in north-east Scotland. Anim Conserv 10:48-56

Thompson D, Bexton S, Brownlow A, Wood D and others (2010) Report on recent seal mortalities in UK waters caused by extensive lacerations. Sea Mammal Research Unit Reports, University of St Andrews

* Tryland M, Kleivane L, Alfredsson A, Kjeld M, Arnason A, Stuen S, Godfroid J (1999) Evidence of Brucella infection in marine mammals in the North Atlantic Ocean. Vet Rec 144:588-592

* Tryland M, Sørensen KK, Godfroid J (2005) Prevalence of Brucella pinnipediae in healthy hooded seals (Cystophora cristata) from the North Atlantic Ocean and ringed seals (Phoca hispida) from Svalbard. Vet Microbiol 105: 103-111

*Van Bressem MF, Van Waerebeek K, Raga JA, Godfroid J, Brew SD, MacMillan AP (2001) Serological evidence of Brucella species infection in odontocetes from the south Pacific and the Mediterranean. Vet Rec 148:657-661

Young EJ (2006) Brucella spp. In: Gillespie SH, Hawkey PM (eds) Principles and practice of clinical bacteriology, $2^{\text {nd }}$ edn. John Wiley \& Sons, Chichester

Zarnke RL, Saliki JT, Macmillan AP, Brew SD and others (2006) Serologic survey for Brucella spp., phocid herpesvirus-1, phocid herpesvirus-2, and phocine distemper virus in harbour seals from Alaska, 1976-1999. J Wildl Dis 42:290-300

Submitted: May 18, 2017; Accepted: August 2, 2017

Proofs received from author(s): September 4, 2017 